\title{
Multi-drug resistance in a canine lymphoid cell line due to increased P-glycoprotein expression, a potential model for drug-resistant canine lymphoma
}

\author{
M. Zandvliet ${ }^{\mathrm{a}, *}$, E. Teske ${ }^{\mathrm{a}}$, J.A. Schrickx ${ }^{\mathrm{b}}$ \\ ${ }^{a}$ Department of Clinical Sciences of Companion Animals, Faculty of Veterinary Medicine, Utrecht University, Yalelaan 108, P.0. Box 80154, 3508 TD Utrecht, The Netherlands \\ ${ }^{\mathrm{b}}$ IRAS Veterinary Pharmacology, Pharmacotherapy and Toxicology, Faculty of Veterinary Medicine, Utrecht University, Yalelaan 104, 3584 CM Utrecht, The Netherlands
}

\section{A R T I C L E I N F O}

\section{Article history:}

Received 3 January 2014

Accepted 19 June 2014

Available online 26 June 2014

\section{Keywords:}

Canine lymphoma

In vitro

Multidrug-resistance model

ABC-transporters

P-glycoprotein

\begin{abstract}
A B S T R A C T
Canine lymphoma is routinely treated with a doxorubicin-based multidrug chemotherapy protocol, and although treatment is initially successful, tumor recurrence is common and associated with therapy resistance. Active efflux of chemotherapeutic agents by transporter proteins of the ATP-Binding Cassette superfamily forms an effective cellular defense mechanism and a high expression of these transporters is frequently observed in chemotherapy-resistant tumors in both humans and dogs.

In this study we describe the ABC-transporter expression in a canine lymphoid cell line and a sub-cell line with acquired drug resistance following prolonged exposure to doxorubicin. This sub-cell line was more resistant to doxorubicin and vincristine, but not to prednisolone, and had a highly increased P-glycoprotein (P-gp/abcb1) expression and transport capacity for the P-gp model-substrate rhodamine123. Both resistance to doxorubicin and vincristine, and rhodamine123 transport capacity were fully reversed by the P-gp inhibitor PSC833. No changes were observed in the expression and function of the ABC-transporters MRP-1 and BCRP.

It is concluded that GL-40 cells represent a useful model for studying P-gp dependent drug resistance in canine lymphoid neoplasia, and that this model can be used for screening substances as potential P-gp substrates and their capacity to modulate P-gp mediated drug resistance.
\end{abstract}

(c) 2014 Elsevier Ltd. All rights reserved.

\section{Introduction}

Canine lymphoma (cL), the most common hematopoietic neoplasia in the dog, is in many respects comparable to non-Hodgkin lymphoma in humans (Teske, 1994). As in humans, treatment in the dog consists of a multidrug chemotherapy protocol that includes, as a minimum, cyclophosphamide, doxorubicin, vincristine and prednisolone (or CHOP-protocol) (Garrett et al., 2002; Sorenmo et al., 2010) of which, as a single agent, doxorubicin appears most effective (Simon et al., 2008). Despite a high initial response rate, tumor relapse is common and more often refractory to therapy, leading to treatment failure and ultimately the dog's death (Flory et al., 2011; Zandvliet et al., 2013). The main cause for treatment failure is thought to be tumor drug resistance (DR) that can be present at the start of chemotherapy (intrinsic DR) or develop during or following chemotherapy (acquired DR). Several clinical studies on cL (Price et al., 1991; Piek et al., 1999; Gavazza et al., 2008; Marconato et al., 2011) have documented that

\footnotetext{
* Corresponding author. Tel.: +31 30 2539411; fax: +31302518126

E-mail address: M.Zandvliet@uu.nl (M. Zandvliet).
}

treatment with glucocorticoids prior to starting chemotherapy lowers the overall response rate and shortens survival and this has been explained by assuming acquired, glucocorticoid-induced DR (Mealey et al., 2003).

One of the mechanisms underlying DR is the active efflux of (cytotoxic) drugs by membrane bound transporter proteins of the ATP-Binding Cassette (ABC) superfamily (Gottesman, 2002; Huang et al., 2004). High expression of these ABC-transporters, and P-glycoprotein (P-gp; ABCB1) in particular, has been associated with both a decreased sensitivity to cytotoxic agents, as well as a poor prognosis in several types of cancer in humans (Huang et al., 2004; Gottesman et al., 2002; Kourti et al., 2007; Efferth et al., 2008) and dogs (Bergman et al., 1996; Lee et al., 1996; Steingold et al., 1998; Honscha et al., 2009). Other ABC-transporters associated with DR to cytotoxic agents in humans include multidrug resistance related protein 1 (MRP1; ABCC1) and breast cancer resistance protein (BCRP; ABCG2) (Gillet et al., 2007), both of which have been studied in veterinary medicine (Honscha et al., 2009; Tashbaeva et al., 2007; Schrickx and Fink-Gremmels, 2008; Mealey, 2012), but not in relation to cL. 
Although DR represents a major obstacle in the successful management of cancer with chemotherapy in both humans and dogs, therapeutic measures to circumvent DR are still limited (Szakacs et al., 2006). Studying the mechanisms responsible for DR will provide a better understanding of DR (Chen and Sikic, 2012) and could potentially lead to the development of new therapies (Efferth et al., 2008; Zhu et al., 2009). For the dog both these goals would be greatly facilitated with a canine in vitro model, but a previously reported DR cell line (Uozurmi et al., 2005) derived from the canine lymphoid GL-1 cell line (Nakaichi et al., 1996) is no longer available.

The first goal of the current study was to re-establish a DR canine lymphoid cell line through selection for doxorubicinresistance. Doxorubicin was purposefully chosen given its' efficacy in the treatment of $\mathrm{CL}$, but also because resistance to doxorubicin is predictive for multidrug resistance in human neoplasia (Efferth et al., 2008). The second goal was to assess in both the original and the doxorubicin resistant sub-cell line, the antiproliferative effect of the drugs used in a CHOP-protocol, and the expression and function of the ABC-transporters P-gp, MRP1 and BCRP in both cell lines.

\section{Material and methods}

\subsection{Chemicals}

PSC833 (Valspodar $^{\circledR}$ ) was a gift from Novartis Pharma AG (Basel, Switzerland) and Ko143 was kindly provided by Prof. Koomen (University of Amsterdam, the Netherlands). MK571 sodium salt was obtained from Alexis Biochemicals (Grünberg, Germany). Rhodamine 123 (Rh123), and 5(6)-carboxyfluorescein diacetate (CFDA) were purchased from Sigma-Aldrich (St Louis, MO, USA). Pheophorbide A (PhA) was obtained from Frontier Scientific (Logan, USA). Doxorubicin hydrochloride and vincristine sulfate and prednisolone were purchased from Sigma-Aldrich (St Louis, MO, USA).

\subsection{Cell lines, cell culture media and supplements}

The canine lymphoid cell-line, GL-1 cells (Nakaichi et al., 1996), was kindly provided by dr K. Ohno (University of Tokyo). The cells were confirmed to be of canine origin through DNA-sequencing (four regions, 900 base-pairs in total) and showed 100\% homology with the canine reference genome. GL-1 cells grow in single cell suspension and showed strong immunoreactivity with CD34 and CD79 $\alpha$, a weak reaction with CD3 and CD4 and no reaction with CD21 and CD90, consistent with a precursor lymphoid cell of the B-lineage.

GL-1 cells were grown in suspension on RPMI 1640 (Gibco, Grand Island, NY, USA) supplemented with $1 \%(\mathrm{v} / \mathrm{v})$ L-glutamine (BioWhittaker, Maine, USA), 10\% (v/v) fetal bovine serum (Gibco) and $100 \mathrm{U} / \mathrm{mL}$ penicillin and $100 \mu \mathrm{g} / \mathrm{ml}$ streptomycin (BioWhittaker) at $37^{\circ} \mathrm{C}, 5 \% \mathrm{CO}_{2}$. The GL-1 cells were cultured with gradually increasing concentrations of doxorubicin and after 6 months a subline of the GL- 1 cells was selected that could be cultured in the presence of $0.07 \mu \mathrm{M}(40 \mathrm{ng} / \mathrm{mL}$, hence GL-40) doxorubicin. Multiple batches of these GL-40 cells were stored in liquid nitrogen and were maintained in culture after thawing following a schedule of one passage with doxorubicin $(20 \mathrm{ng} / \mathrm{mL})$ and two passages without doxorubicin

\subsection{Proliferation assay}

Cell proliferation was assessed with the Cell Counting Kit-8 assay (CCK-8, Dojindo Molecular Technologies, Rockville,
Maryland, USA) using the tetrazolium salt, WST-8 (2-(2-methoxy-4-nitrophenyl)-3-(4-nitrophenyl)-5-(2,4-disulfophenyl)-2Htetrazolium, monosodium salt), which produces a water-soluble formazan dye following bioreduction in the presence of the electron carrier, 1-methoxy PMS. Cells were seeded in 96-well plates at a density of $2 \times 10^{4}$ cells per well in cell culture medium containing a concentration range of doxorubicin, vincristine or prednisolone and incubated for 24,47 , and $72 \mathrm{~h}$ at $37{ }^{\circ} \mathrm{C}, 5 \% \mathrm{CO}_{2}$. The tetrazolium solution was added to each well $2 \frac{1}{2} \mathrm{~h}$ before light absorbance analysis. The formation of the soluble formazan was measured by light absorbance at $450 \mathrm{~nm}$ in a microplate reader. Cell proliferation was calculated by dividing the light absorbance in treated cells by that in control cells after correction for background absorbance.

Concentration dependent effects were analyzed by non-linear regression after log transformation of the concentration and graphs were fitted according to a sigmoïd dose-response curve. A timedependent effect was observed on GL-cell proliferation and results were reported after $72 \mathrm{~h}$ of incubation.

\subsection{RNA isolation and synthesis of $c D N A$}

Total RNA was isolated using the SV-total RNA isolation kit (Promega, Leiden, The Netherlands) according to the manufacturer's protocol including a DNAse treatment. The RNA was quantified spectrophotometrically at $260 \mathrm{~nm}$ (ND-1000, Nanodrop technologies) and stored at $-70^{\circ} \mathrm{C}$.

First strand cDNA from $1 \mu \mathrm{g}$ total RNA was synthesized with the iScript $^{\mathrm{TM}}$ cDNA Synthesis kit (Bio-Rad, Hercules, CA, USA) containing both oligo $(\mathrm{dT})$ and random hexamer primers in a final volume of $20 \mu \mathrm{L}$ according the manufacture's recommendation. The cDNA was stored at $-20^{\circ} \mathrm{C}$.

\subsection{Real time quantitative PCR analysis}

Gene-specific primers were developed, commercially synthesized (Eurogentec, Maastricht, the Netherlands) and tested for efficiency by using a dilution series of cDNA. The efficiency of the primers was between $95 \%$ and $105 \%$ and only one product was formed as assessed by melting curve analysis. $50 \mathrm{ng}$ reverse transcribed RNA, 7.5 pmol of each gene-specific primer (Table 1) and $\mathrm{IQ}^{\mathrm{TM}}$ SybrGreen Supermix (Biorad) in a final $25 \mu \mathrm{L}$ reaction volume was analyzed by quantitative PCR in a MyIQ single color real time PCR detection system (BioRad). Following an initial hot start for 3 min, 40 cycles were run with a denaturation step at $95^{\circ} \mathrm{C}$ for $20 \mathrm{~s}$, an annealing step at $63^{\circ} \mathrm{C}$ for $30 \mathrm{~s}$ and an elongation step at $72{ }^{\circ} \mathrm{C}$ for $30 \mathrm{~s}$.

\subsection{Immunocytochemistry}

For the immunocytochemical detection of ABC-transporters in the GL- 1 and GL-40 cells, cytospin smears were prepared by placing $5 \times 10^{5}$ cells in culture medium into a cytology funnel with pre-attached filtercard (Biomedical Polymers Inc, Gardner (MA), USA) that was fixed with a funnel clip onto a polysine microscope slide (Menzel-Gläser, Braunschweig, Germany) and centrifuged at $650 \mathrm{rpm}$ for $10 \mathrm{~min}$ in a cytospin centrifuge (Thermo Scientific ${ }^{\mathrm{TM}}$ Cytospin $^{\mathrm{TM}} 4$ Cytocentrifuge, Thermo Shandon Limited, Runcorn, UK). The freshly prepared cytospin preparations $\left(1 \times 10^{6}\right.$ cells/slide $)$ were air dried, followed by a 3 min fixation step in acetone. After rehydration in phosphate-buffered saline (PBS) and incubation with $10 \%$ swine serum in PBS (20 min), endogenous peroxidase activity was blocked with $0.3 \% \mathrm{H}_{2} \mathrm{O}_{2}$ in methanol (Cell Marque, Rocklin, CA, USA) for $10 \mathrm{~min}$. Slides were then incubated with mouse antibodies directed against human P-gp (Van der Heyden et al., 2011) (C494, Alexis Switzerland), MRP1 (Scheffer 
Table 1

Primer details.

\begin{tabular}{|c|c|c|c|c|c|}
\hline Canine gene & GenBank & Forward primer & Reverse primer & Product size & $T_{a}\left({ }^{\circ} \mathrm{C}\right)$ \\
\hline Abcb1 (P-gp) & NM_001003215 & CTATGCCAAAGCCAAAGTATC & GAGGGCTGTAGCTGTCAATC & 80 & 57.5 \\
\hline Abcc1 (MRP1) & NM_001002971 & CGTGACCGTCGACAAGAACA & CACGATGCTGATGACCA & 118 & 60.9 \\
\hline Abcg2 (BCRP) & NM_001048021 & GGTATCCATAGCAACTCTCCTCA & GCAAAGCCGCATAACCAT & 146 & 60.0 \\
\hline
\end{tabular}

et al., 2000) ( $\mathrm{M}_{2}$ III-6, kind gift by dr Scheffer, the Netherlands) and BCRP (Maliepaard et al., 2001) (BXP-21, Abcam, UK) for $1 \mathrm{~h}$ at room temperature. Antibody binding was detected by polyvalent biotinylated serum, HRP-labeled streptavidin and diaminobenzidine as a chromogen (Cell Marque, Rocklin, CA, USA). Following a 10-min wash in aqua dest, counterstaining was performed with hematoxyline solution according to Mayer (Sigma, St Louis, MO, USA) for $3 \mathrm{~min}$, followed by a 2 -min washing step in aqua dest.

\subsection{Functional studies with fluorescent transporter substrates and selective inhibitors}

Functional studies were performed using the typical fluorescent substrate-inhibitor combinations Rh123-PSC833 for assessing P-gp, CFDA-MK571 for MRP, and PhA-Ko143 for BCRP function (Allen et al., 2002; Dogan et al., 2004; Schleis et al., 2008). All experiments with GL-40 cells were performed with cells that had been incubated for one passage without doxorubicin. Before the GL-1 and GL-40 cells were used in experiments with fluorescent dyes, cell viability was assessed with trypan blue exclusion and cell numbers were counted in a hematocytometer. A total of $5 \times 10^{5}$ viable cells per sample were plated into 96 -well plates. In the transport studies, culture medium was replaced by Hanks Balanced Salt Solution (HBSS) without $\mathrm{Ca}^{2+}, \mathrm{Mg}^{2+}$ and phenol red and with $1000 \mathrm{mg} / \mathrm{L}$ glucose (Gibco, Grand Island, NY, USA). All chemicals were dissolved in DMSO as $1.000 \times$ stock solutions resulting in a final concentration of DMSO of $0.1 \%$ for all samples.

P-gp and BCRP transporter activity were assessed in an efflux assay. A total of $5 \times 10^{5}$ viable cells per sample were plated into 96-well plates and after centrifugation ( $50 \mathrm{~g}, 3 \mathrm{~min}$ ) culture medium was replaced by HBSS containing Rh123 ( $4 \mu \mathrm{mol} / \mathrm{L})$ or $\mathrm{PhA}$ $(0.1-1 \mu \mathrm{mol} / \mathrm{L})$ and cells were incubated for $30 \mathrm{~min}\left(37^{\circ} \mathrm{C}, 5 \%\right.$ $\mathrm{CO}_{2}$ ). Following this loading, cells were washed twice in PBS (Gibco, Grand Island, NY, USA) by centrifugation and the cell pellets were re-suspended in HBSS containing a concentration range of PSC833 or Ko143 as indicated in the results section. Incubation was continued for a further two hours, after which cell-suspensions were pelleted by centrifugation $\left(4^{\circ} \mathrm{C}\right)$ and the medium was replaced by dye-free HBSS $\left(4^{\circ} \mathrm{C}\right)$. These cell suspensions were collected and transferred into FACS-tubes and placed on ice until FACS analysis.

P-gp and BCRP transporter activity were also assessed in an uptake study. MRP activity was assessed only in a CFDA uptake study. In contrast to Rh123 and PhA, CFDA requires cleavage by intracellular esterases to generate $\mathrm{CF}$, the fluorescent product measured in the uptake study. In order to demonstrate substrate and inhibitor specificity, a concentration series of the P-gp inhibitor PSC833 and the MRP inhibitor MK571 were tested in combination with Rh123 and CFDA. For the fluorescent dye accumulation assays, culture medium was replaced by HBSS containing the fluorescent transporter substrate dye and an inhibitor. After 30 min of incubation $\left(37^{\circ} \mathrm{C}, 5 \% \mathrm{CO}_{2}\right)$, culture medium was replaced by PBS $\left(4{ }^{\circ} \mathrm{C}\right)$ and the cell suspensions were transferred into FACS-tubes and placed on ice until FACS analysis.

A flow cytometer (FACS Calibur, Biorad, The Netherlands) equipped with an argon $488 \mathrm{~nm}$ laser was used to analyze the samples. Cell-associated fluorescence of Rh123 and CF was measured using a 530-nm bandpass filter and cell-associated $\mathrm{PhA}$ fluorescence was measured using a 610-nm longpass filter. The samples were gated on forward scatter versus side scatter to exclude clumps and cell debris. Data were collected for a minimum of 10,000 gated events per sample.

\subsection{FACS data analysis}

FACS data represent the geometric mean cell-associated fluorescence intensity and are reported in Relative Fluorescence Units (RFU). Changes in the cellular accumulation (Rh123, CF or PhA) by the inhibitors were presented as RFU. Efflux (Rh123, PhA) was calculated according to Eq. (1) and expressed as a percentage with one hundred percent efflux meaning that after two hours of incubation no fluorescence was measured within the cells and zero percent efflux meaning that all fluorescence was retained within the cells due to efflux inhibition.

Efflux $=\left[\left(\mathrm{FL}_{0}-\mathrm{FL}_{\mathrm{B}}\right)-\left(\mathrm{FL}_{120}-\mathrm{FL}_{\mathrm{B}}\right)\right] /\left(\mathrm{FL}_{0}-\mathrm{FL}_{\mathrm{B}}\right) \times 100 \%$

$\mathrm{FL}_{0}$ is the Fluorescence intensity at $t=0 \mathrm{~min}, \mathrm{FL}_{\mathrm{B}}$ is the Fluorescence intensity of the background, and $\mathrm{FL}_{120}$ is the Fluorescence intensity of the samples at $t=120 \mathrm{~min}$.

\subsection{Glucocorticoid receptor assay}

The presence of a functional glucocorticoid receptor was assessed in both GL- 1 and GL-40 cells using a luciferase assay as previously described by Gracanin et al., 2012. In short, GL-cells $\left(8 \times 10^{5}\right.$ cells/well $)$ were seeded in 24-well plates and transfected using per well $2 \mu \mathrm{L}$ Lipofectamine 2000 (Invitrogen, Bleiswijk, the Netherlands), $800 \mathrm{ng}$ of Mouse Mammary Tumor Virus (MMTV)-luciferase containing a glucocorticoid receptorresponsive reporter, and $0.3 \mathrm{ng}$ of human $\beta$-actin-promoter renilla as an internal control. Following transfection the cells were left to recover for $24 \mathrm{~h}$ and then incubated with prednisolone $(0.1 \mu \mathrm{mol} / \mathrm{L})$ for $24 \mathrm{~h}$. Firefly and renilla luciferase activities were subsequently quantified using a Dual-Luciferase Assay System (Promega, Leiden, the Netherlands) in a Centro LB 960 luminometer (Berthold Technologies, Vilvoorde, Belgium). The canine mammary cell line CNMm was used as a positive control.

\subsection{Effect of prednisolone on ABC-transporter expression}

The cells were incubated with a concentration range of prednisolone for 3, 6 and $24 \mathrm{~h}$ in cell culture medium (RPMI 1640). At the time of sampling, the cells were harvested by centrifugation, medium was discarded and the cell pellet was lysed in Promega lysis buffer. RNA isolation, cDNA synthesis and quantitative PCR analysis were performed as described above. Results are reported as Relative Expression that was calculated according to Eq. (2).

Relative Expression $=2 \wedge\left(\mathrm{Ct}_{\text {mean }}-\mathrm{Ct}_{\text {sample }}\right)$

$\mathrm{Ct}_{\text {mean }}$ is the mean $\mathrm{Ct}$ value at $t=0 \mathrm{~h}$ for each $\mathrm{ABC}$ transporter for GL-1 or GL-40, and $\mathrm{Ct}_{\text {sample }}$ is the mean Ct value at $t=3,6$ or $24 \mathrm{~h}$ for each $A B C$ transporter for GL-1 or GL-40.

\subsection{Statistical analysis}

All experiments were repeated independently for three times. Differences in accumulation or efflux of fluorescent dyes in the 
absence or presence of a specific transporter inhibitor were analyzed for statistic significance using the One-Way ANOVA with Dunnett multiple comparison post hoc test. The level of significance was set at $P<0.05$ and significant differences are mentioned in the text. All statistical analyses were performed using Graph Pad Prism software (San Diego, California, USA).

\section{Results}

3.1. GL-40. cells are resistant to doxorubicin and vincristine, but not prednisolone

The sub-cell line GL-40 was selected from GL-1 cells through intermittent incubation with gradually increasing concentrations of doxorubicin over a 6-month period and resulted with an increase in $\mathrm{IC}_{50}$-doxorubicin from $17.2 \mathrm{nmol} / \mathrm{L}$ for $\mathrm{GL}-1$ cells to $115 \mathrm{nmol} / \mathrm{L}$ for GL-40 cells. GL-40 cell showed resistance to vincristine with an $\mathrm{IC}_{50}$-vincristine $0.54 \mathrm{nmol} / \mathrm{L}$ for $\mathrm{GL}-1$ cells and $21.4 \mathrm{nmol} / \mathrm{L}$ for GL-40 cells (Fig. 1, Table 2). Prednisolone caused a mild (35\%), but significant decrease in cell proliferation that was similar in both GL cell lines (Fig. 2).

\subsection{Immunocytochemistry of $A B C$-transporters $P$-gp, MRP1 and $B C R P$}

P-gp expression was detected using the monoclonal antibody C494 and appeared more intense in GL-40 than GL-1 cells (Fig. 3). Using the monoclonal antibody M2III-6, MRP1 expression was demonstrated in both cell lines, but appeared more intense in GL-1 cells (Fig. 3). BCRP expression, using the monoclonal antibody BXP-21, was similar in both cell lines (Fig. 3).
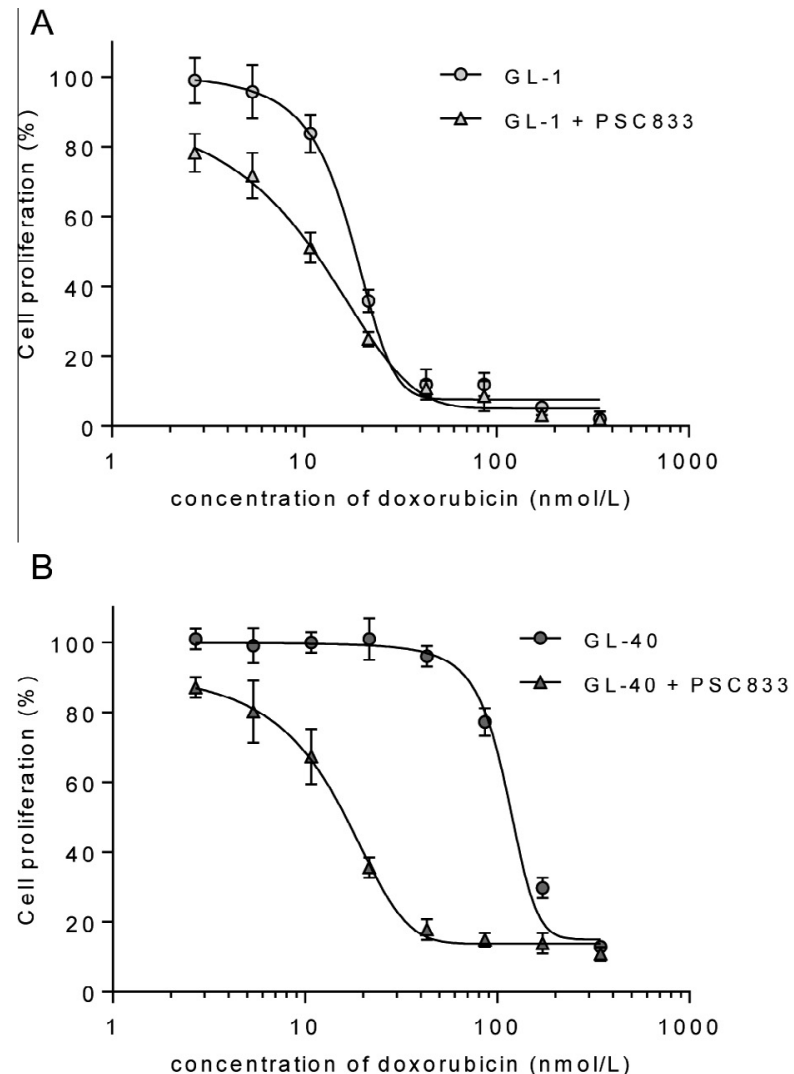

Table 2

Drug sensitivity represented by $\mathrm{IC}_{50}$-values ( $\mathrm{nM}$; mean with $95 \%$ confidence intervals) in the GL- 1 and GL-40 cells for doxorubicin and vincristine and the effect of PSC833 (1 M).

\begin{tabular}{llll}
\hline Drug & PSC833 & GL-1 & GL-40 \\
\hline Doxorubicin (nM) & - & $17.2(15.0-19.5)$ & $115(109-120)$ \\
& + & $13.3(10.7-16.6)$ & $15.8(15.3-16.6)$ \\
Vincristine (nM) & - & $0.54(0.52-0.57)$ & $21.4(16.9-27.2)$ \\
& + & $0.32(0.31-0.33)$ & $0.31(0.31-0.32)$ \\
\hline
\end{tabular}

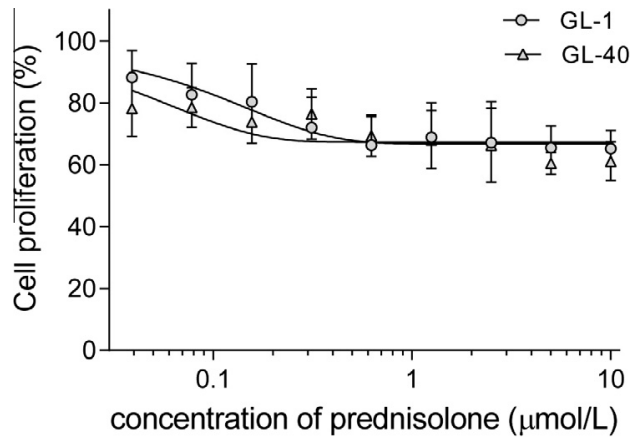

Fig. 2. Inhibition of cell proliferation by prednisolone in GL-1 and GL-40 cells. Data are presented as mean \pm SD of three independent experiments.

\section{3. mRNA expression of the ABC-transporters P-gp, MRP1 and BCRP}

P-gp mRNA expression was significantly lower in GL-1 cells $(\mathrm{Ct} \geqslant 35)$ than in $\mathrm{GL}-40$ cells $(\mathrm{Ct}=22)$, indicating an approximately
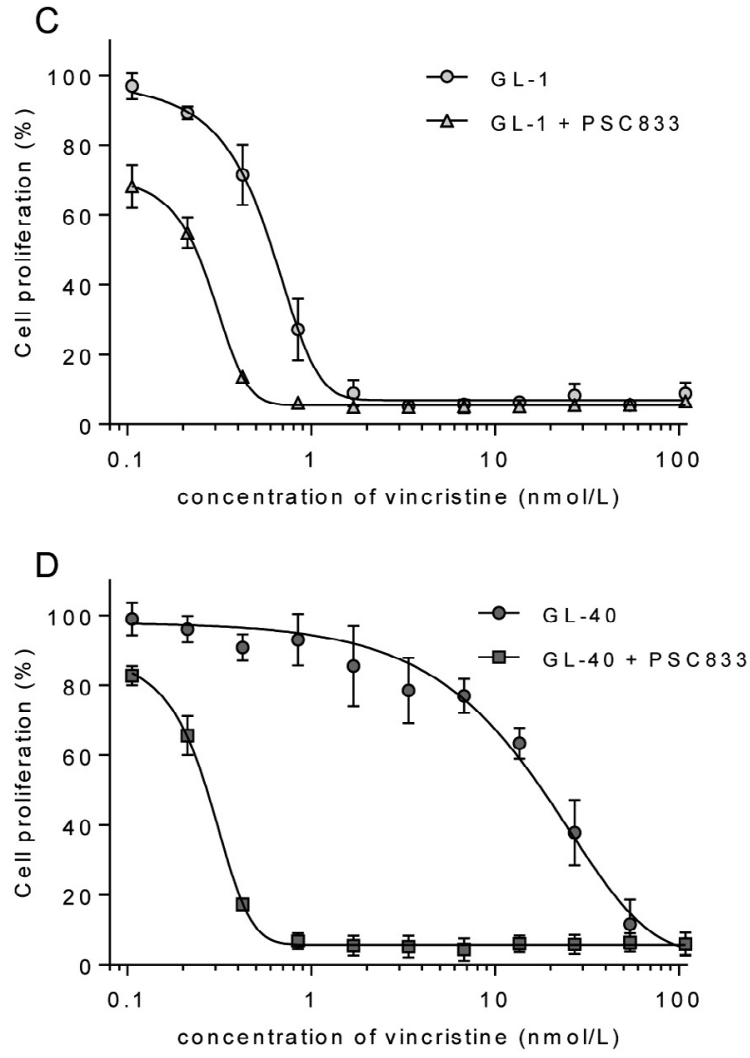

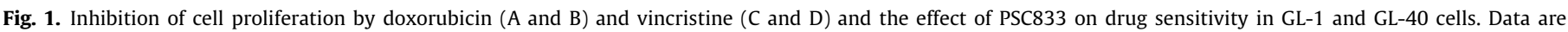
presented as mean \pm SD of three independent experiments. 


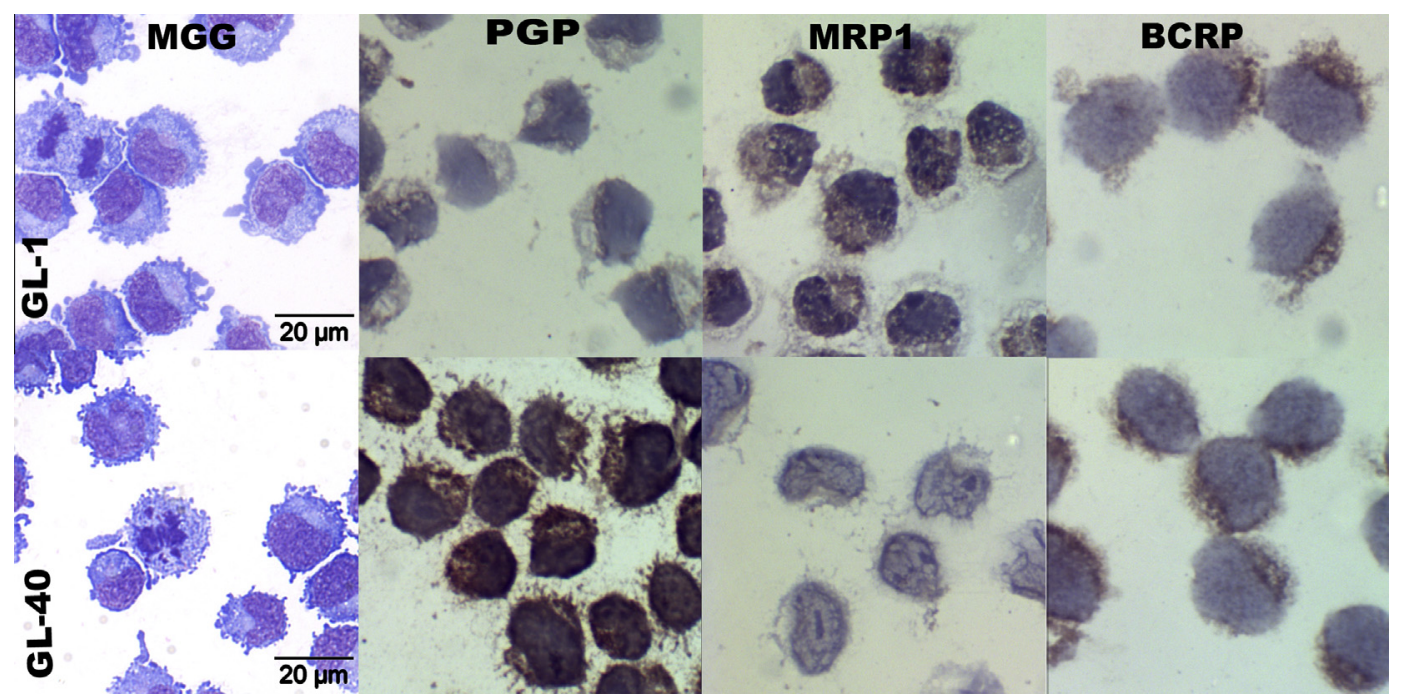

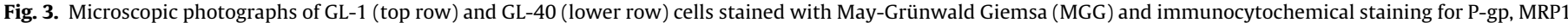
and BCRP (columns).

7500 times higher expression in the latter (Fig. 4). MRP1 and BCRP expression were both detected ( $\mathrm{Ct}$ values of 22 and 23 respectively), but similar in both GL-cell lines.

\subsection{Functional studies for P-gp, MRP and BCRP}

\subsubsection{Rhodamine 123 as a probe dye for Pgp function}

Rhodamine 123 efflux from the GL-40 cells was approximately 4 times higher compared to the GL-1 cells (Fig. 4) and the P-gp-inhibitor PSC833 decreased Rh123 efflux in a concentration dependent fashion in the GL-40 cells ( IC $_{50} 0.05 \mu \mathrm{mol} / \mathrm{L}$ ), but not in the GL-1 cells (Fig. 5).

Rhodamine 123 accumulation was significantly lower in GL-40 compared to GL-1 cells and PSC833 caused a concentration dependent increase in Rh123 accumulation in the GL-40, but not in the GL-1 cells (Fig. 6). Only higher concentrations of MK571 (5 and $25 \mu \mathrm{mol} / \mathrm{L}$ ) significantly increased Rh123 accumulation in the GL-40, but not the GL-1 cells (Fig. 6).

\subsubsection{CFDA as a probe dye for MRP-transporters}

Cellular accumulation of $\mathrm{CF}$ following incubation with CFDA $(1 \mu \mathrm{mol} / \mathrm{L})$ was higher in the GL-40 cells compared to the GL- 1 cells and MK571 increased CF accumulation in a concentration dependent way in both GL cell lines (Fig. 7). The highest PSC833 concentration tested $(1 \mu \mathrm{mol} / \mathrm{L})$ resulted in a minor, but significant, increase in CF accumulation in the GL-1 cells at (Fig. 7).

\subsubsection{Pheophorbide $A$ as a probe dye for BCRP}

$\mathrm{PhA}$ was tested at a concentration range from 0.1 to $1 \mu \mathrm{mol} / \mathrm{L}$ in combination with the BCRP inhibitor Ko143 at $1 \mu \mathrm{mol} / \mathrm{L}$. PhA efflux

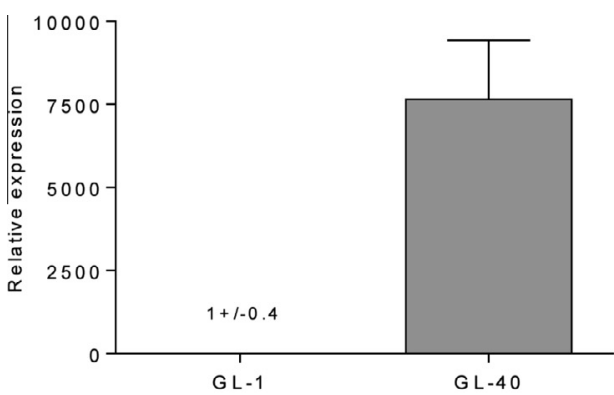

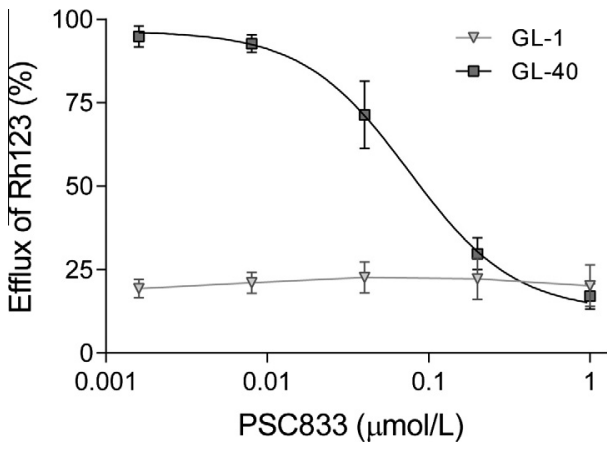

Fig. 5. Efflux of the P-gp substrate rhodamine 123 by GL1 and GL- 40 cells after $2 \mathrm{~h}$ of incubation in dye-free medium with increasing concentrations of PSC833. Data are presented as mean \pm SD of three independent experiments.

(\%) was similar in both GL-1 and GL-40 cells and decreased with increasing concentrations of PhA. Incubation with Ko143 had no effect on PhA efflux (Fig. 8). Cellular accumulation of PhA was comparable for both the GL-1 and GL-40 cell lines (Fig. 8), and Ko143 had no significant effect on the cellular PhA accumulation in either cell-line.

\subsection{Doxorubicin and vincristine resistance in GL-40 cells is reversed by PSC833}

PSC833 $(1 \mu \mathrm{mol} / \mathrm{L})$ restored GL-40's sensitivity to the antiproliferative effects of doxorubicin and vincristine to levels comparable

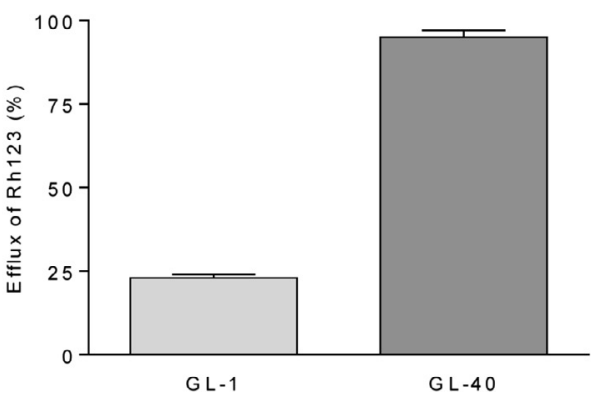

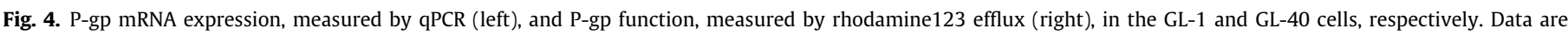
presented as mean \pm SD of three independent experiments. 

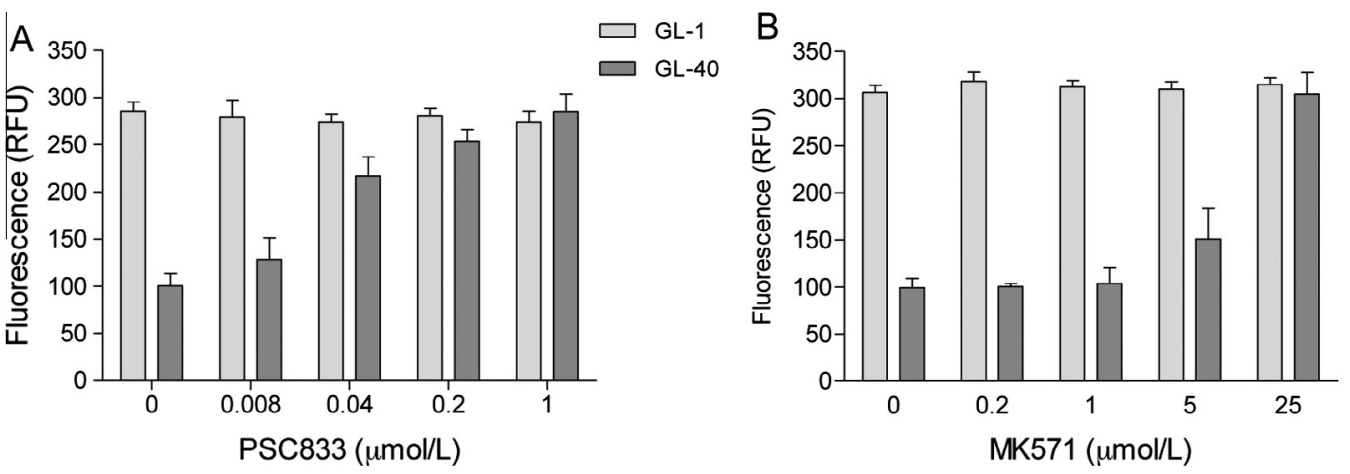

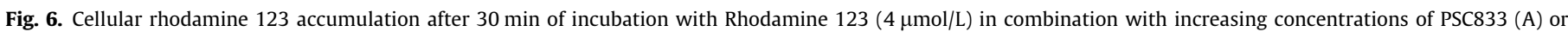
MK571 (B). Data are presented as mean \pm SD of three independent experiments.
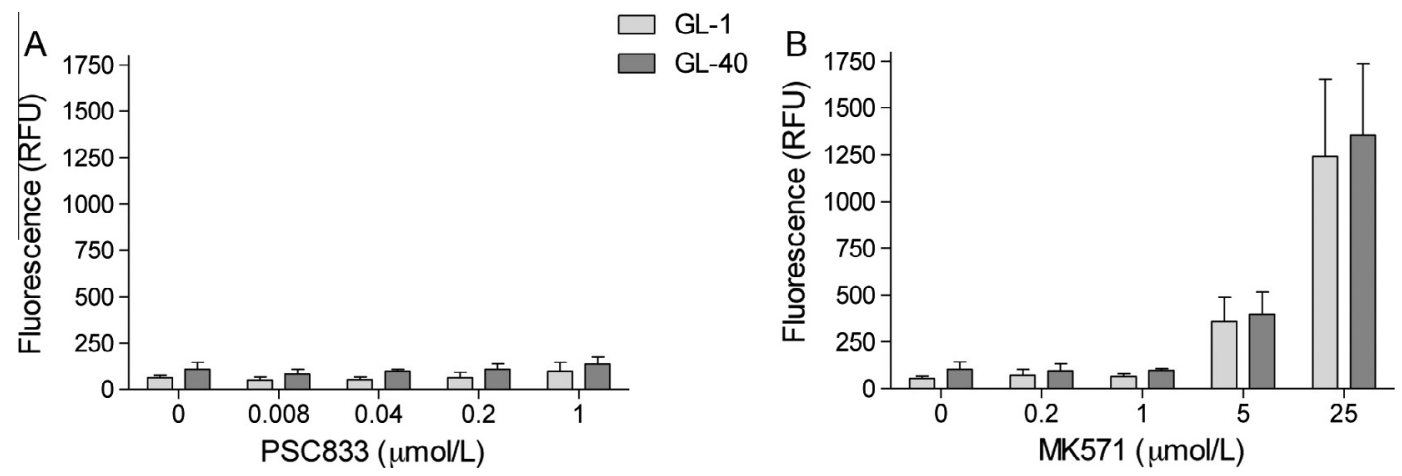

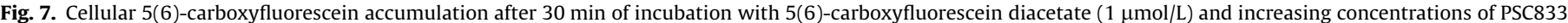
(A) or MK571 (B). Data are presented as mean \pm SD of three independent experiments.
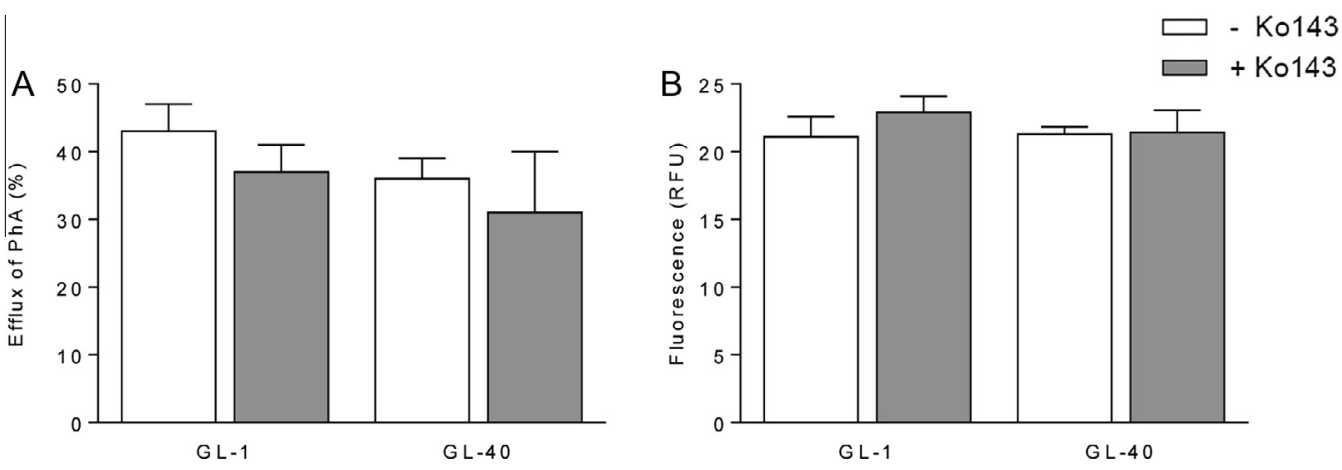

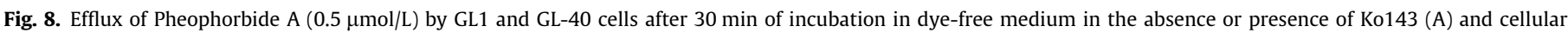

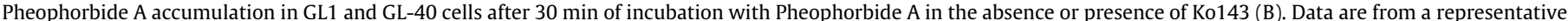
experiment and presented as mean \pm SD.

with GL-1 cells (Table 2). PSC833 alone showed a mild, but equal, antiproliferative effect in both GL cell lines (Fig. 1).

3.6. GL-cells have a functional glucocorticoid-receptor, but prednisolone fails to induce P-gp, MRP1 or BCRP expression

Following transfection of CNMm, GL-1, and GL-40 cells with MMTV-luc, prednisolone $(0.1 \mu \mathrm{M})$ caused a, respectively, 6-, 4-, and 2.6-fold increase in luciferase-activity confirming the presence of active glucocorticoid receptors in both cell-lines.

Short-term incubation (3, 6, $24 \mathrm{~h}$ ) of both GL-1 and GL-40 cells with prednisolone did not significantly change the mRNA expression of P-gp, MRP1, and BCRP (Fig. 9). The low levels of P-gp mRNA expression in the GL- 1 cells $(C t \geqslant 35)$, resulted in a large variation in relative expression results.

\section{Discussion}

Selection for doxorubicin resistance by exposing the canine B-cell lymphoid leukemia cell line GL-1 (Nakaichi et al., 1996) to gradually increasing concentrations of doxorubicin led to the GL-40 sub-cell line that was six times more resistant to doxorubicin and showed cross-resistance to the structurally and mechanistically unrelated cytotoxic agent vincristine. The observed DR corresponded with an increased P-gp expression (mRNA and immunocytochemistry) and transport capacity for the P-gp model 
G L - 1
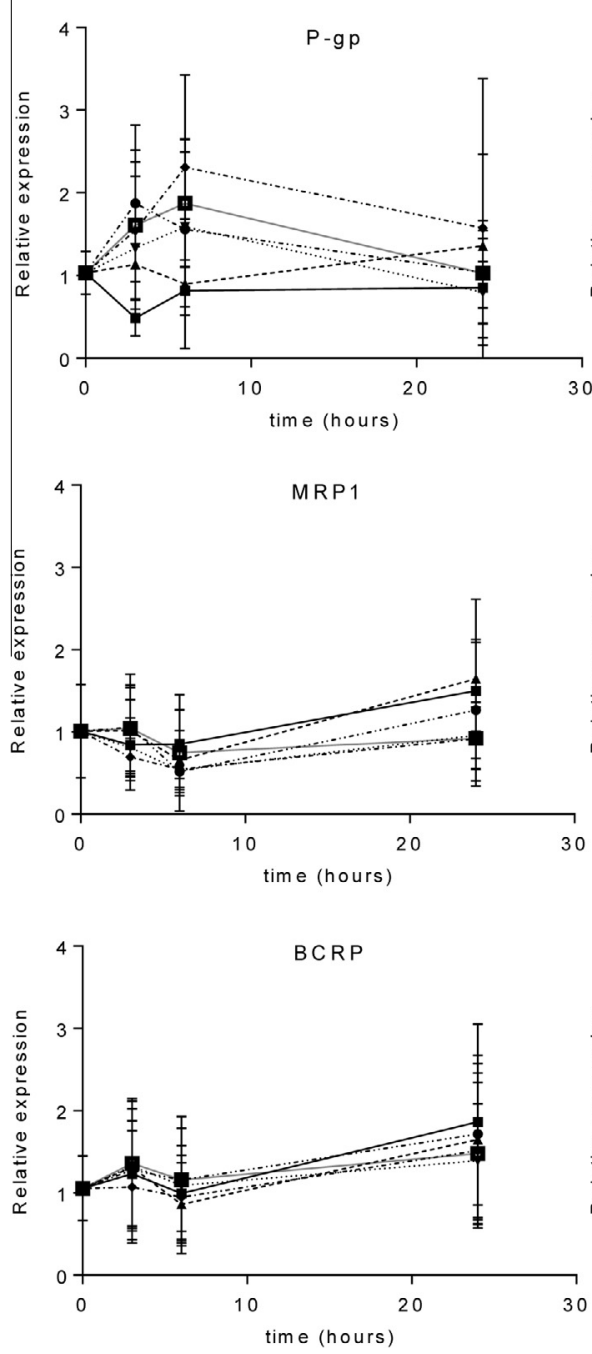

G L - $\mathbf{4 0}$
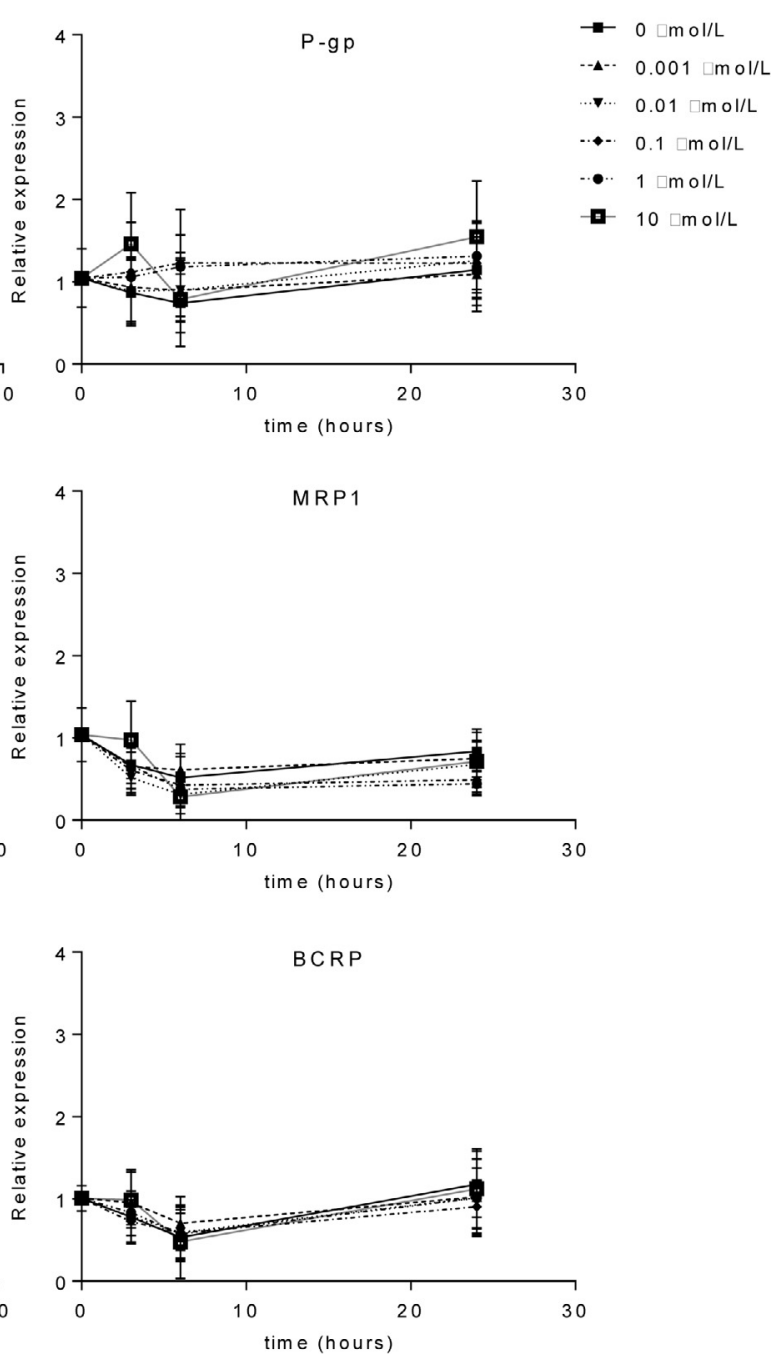

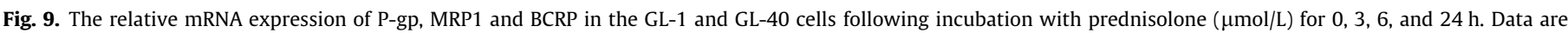
presented as mean \pm SD of three independent experiments.

substrate Rh123. Both DR and Rh123-transport were completely reversed with the prototypical P-gp inhibitor PSC833. Therefore, it is concluded that P-gp causes multi-drug resistance in the GL-40 sub-cell line, which is in line with previous in vitro studies (Uozurmi et al., 2005; Matsuura et al., 2007). Furthermore these results indicate that in the dog, as in humans (Ambudkar et al., 1999), doxorubicin and vincristine are both P-gp substrates. Given the fact that P-gp expression is more prevalent in dogs with relapsed and DR cL (Bergman et al., 1996; Lee et al., 1996; Page et al., 2000), GL-40 cells represent a suitable in vitro model for studying DR in canine lymphoid neoplasia.

Induction of DR through incubation with increasing concentrations of a cytostatic agent, the method used in the current study, has a tendency to preferentially select for P-gp overexpression as the major DR-mechanism and might not necessarily reflect in vivo $\mathrm{DR}$, which can be conveyed through both other effluxtransporters, as well as other mechanisms (Calcagno and Ambudkar, 2010). For example, besides increased P-gp expression, changes in cellular survival signaling cascades, resistance to apoptosis and upregulation of antioxidant defense enzymes (McCubrey et al., 2006; Tome et al., 2012) have been shown to result in DR and these mechanisms might also have contributed to GL-40's DR phenotype.

Other ABC-transporters implicated in DR to cytostatic drugs in humans include MRP1 and BCRP. The canine orthologs of both these transporters have been evaluated in transfected cell lines and have associated MRP1 with resistance to vincristine, but not doxorubicin (Ma et al., 2002) and BCRP with resistance to doxorubicin (Honscha et al., 2009). In the GL-40 cells the level of MRP1 mRNA expression was similar to that of the parental GL-1 cells, although the less intense immunoreactivity and the higher $\mathrm{CF}$ retention in the GL- 40 cells suggest a reduced MRP1 proteinexpression and function. BCRP expression (mRNA, immunocytochemistry) and function (PhA transport) seemed low and equal for both GL cell-lines. Therefore, it can be assumed that neither MRP1, nor BCRP are a cause for GL-40's observed DR.

Prednisolone had a mild and equal antiproliferative effect on both GL-1 and GL-40 cells. The absence of prednisolone resistance in the GL-40 cells is not consistent with the assumption that prednisolone is a P-gp substrate and stands in contrast with human data (Crowe and Tan, 2012) and a canine in vivo study (Van der Heyden et al., 2012). The absence of a functional glucocorticoid 
receptor would explain this finding, but is rejected since a luciferase assay demonstrated activation of glucocorticoid receptor response elements following exposure to prednisolone in both GL cell lines. Alternative mechanisms for this unexpected glucocorticoid resistance would include down-stream effects like resistance to glucocorticoid-induced apoptosis (Schlossmacher et al., 2011). This observation, as well as the cause for the lower luciferase-activity activity in the GL-40 cells, requires further investigation. Furthermore, prednisolone failed to induce expression of P-gp, MRP1 and BCRP mRNA in both GL-1 and GL-40 cells. Based on these data, prednisolone appears neither a substrate for, nor an inducer of P-gp in canine lymphoid cells, which makes the assumption that prednisolone treatment leads to DR through induction of P-gp overexpression unlikely.

In this study PSC833 and MK571 were used as inhibitors for P-gp and MRPs respectively (Dogan et al., 2004; Schleis et al., 2008). Our data show that, in the concentration range tested, PSC833 is a selective inhibitor of canine P-gp with only a mild, and functionally not relevant, inhibition of MRP's at the highest concentration tested. MK571, however, has a comparable effect on Rh123 and CF accumulation in both cell lines suggesting comparable inhibitory potencies towards P-gp and MRP's, as was previously shown for the human homologue transporters (Matsson et al., 2009). The combination of PhA with Ko143 at $1 \mu \mathrm{mol} / \mathrm{L}$, a concentration expected to fully block BCRP (Allen et al., 2002) was tested, but the differences in PhA accumulation between the two GL-cell lines and the effect of Ko143 on PhA accumulation were small and not statistically different. Further studies are needed to demonstrate their use for assessing canine BCRP function.

Because of the common observation of elevated levels of P-gp in multidrug resistant human cancers, significant effort has been spent on developing potent and selective compounds that can modulate P-gp function without undesirable toxicity like PSC833 (Darby et al., 2011). The highly increased Rh123 efflux and P-gp expression in the GL-40 cells makes these cells a good model for studying interactions of these compounds with canine P-gp. Next to P-gp inhibition, PSC833 is also capable of inducing apoptosis in human leukemia T-cells by increasing cellular ceramide levels (Azare et al., 2001). An inhibitory effect of PSC833 on lymphoid cell proliferation was also observed in the current study, which appears independent of P-gp function since both GL-1 and GL-40 cells appeared equally sensitive.

In conclusion, P-gp appears to play an important role in multidrug resistance in canine lymphoid neoplasia, and we present a canine (lymphoid) cell model that allows for the study of multidrug resistance in vitro as well as the effect of MDR-modulators thereon.

\section{Conflict of Interest}

The authors declare that there are no conflicts of interest.

\section{Transparency Document}

The Transparency document associated with this article can be found in the online version.

\section{Acknowledgements}

The authors thank Marjolein Oosterveer-van der Doelen and Janneke Olde-Loohuis for their skillful technical assistance with the cytotoxicity and transport assays. Dr Peter Leegwater is greatly acknowledged for confirming the GL-cells' canine origin through DNA-sequencing and dr Jan Mol for performing the glucocorticoid receptor assay.

\section{References}

Allen, J.D., van Loevezijn, A., Lakhai, J.M., van der Valk, M., van Tellingen, O., Reid, G. Schellens, J.H., Koomen, G.J., Schinkel, A.H., 2002. Potent and specific inhibition of the breast cancer resistance protein multidrug transporter in vitro and in mouse intestine by a novel analogue of fumitremorgin C. Mol. Cancer. Ther. 1, 417-425.

Ambudkar, S.V., Dey, S., Hrycyna, C.A., Ramachandra, M., Pastan, I., Gottesman, M.M., 1999. Biochemical, cellular, and pharmacological aspects of the multidrug transporter. Annu. Rev. Pharmacol. Toxicol. 39, 361-398.

Azare, J., Pankova-Kholmyansky, I., Salnikow, K., Cohen, D., Flescher, E., 2001. Selective susceptibility of transformed T lymphocytes to induction of apoptosis by PSC 833, an inhibitor of P-glycoprotein. Oncol. Res. 12, 315-323.

Bergman, P.J., Ogilvie, G.K., Powers, B.E., 1996. Monoclonal antibody C219 immunohistochemistry against P-glycoprotein: sequential analysis and predictive ability in dogs with lymphoma. J. Vet. Int. Med. 10, 354-359.

Calcagno, A.M., Ambudkar, S.V., 2010. Molecular mechanisms of drug resistance in single-step and multi-step drug-selected cancer cells. Methods Mol. Biol. 596, 77-93.

Chen, K.G., Sikic, B.I., 2012. Molecular pathways: regulation and therapeutic implications of multidrug resistance. Clin. Cancer Res. 18, 1863-1869.

Crowe, A., Tan, A.M., 2012. Oral and inhaled corticosteroids: differences in Pglycoprotein (ABCB1) mediated efflux. Toxicol. Appl. Pharmacol. 260, 294-302.

Darby, R.A., Callaghan, R., McMahon, R.M., 2011. P-glycoprotein inhibition: the past, the present and the future. Curr. Drug Metab. 12, 722-731.

Dogan, A.L., Legrand, O., Faussat, A.M., Perrot, J.Y., Marie, J.P., 2004. Evaluation and comparison of MRP1 activity with three fluorescent dyes and three modulators in leukemic cell lines. Leuk. Res. 28, 619-622.

Efferth, T., Konkimalla, V.B., Wang, Y.F., Sauerbrey, A., Meinhardt, S., Zintl, F., Mattern, J., Volm, M., 2008. Prediction of broad spectrum resistance of tumors towards anticancer drugs. Clin. Cancer Res. 14, 2405-2412.

Flory, A.B., Rassnick, K.M., Erb, H.N., Garrett, L.D., Northrup, N.C., Selting, K.A., Phillips, B.S., Locke, J.E., Chretin, J.D., 2011. Evaluation of factors associated with second remission in dogs with lymphoma undergoing retreatment with a cyclophosphamide, doxorubicin, vincristine, and prednisone chemotherapy protocol: 95 cases (2000-2007). J. Am. Vet. Med. Assoc. 238, 501-506.

Garrett, L.D., Thamm, D.H., Chun, R., Dudley, R., Vail, D.M., 2002. Evaluation of a 6-month chemotherapy protocol with no maintenance therapy for dogs with lymphoma. J. Vet. Int. Med. 16, 704-709.

Gavazza, A., Lubas, G., Valori, E., Gugliucci, B., 2008. Retrospective survey of malignant lymphoma cases in the dog: clinical, therapeutical and prognostic features. Vet. Res. Commun. 32 (Suppl 1), S291-S293.

Gillet, J.P., Efferth, T., Remacle, J., 2007. Chemotherapy-induced resistance by ATPbinding cassette transporter genes. Biochim. Biophys. Acta 1775, 237-262.

Gottesman, M.M., 2002. Mechanisms of cancer drug resistance. Annu. Rev. Med. 53. 615-627.

Gottesman, M.M., Fojo, T., Bates, S.E., 2002. Multidrug resistance in cancer: role of ATP-dependent transporters. Nat. Rev. Cancer 2, 48-58.

Gracanin, A., van Wolferen, M.E., Sartorius, C.A., Brenkman, A.B., Schoonen, W.G. Mol, J.A., 2012. Canid progesterone receptors lack activation function 3 domaindependent activity. Endocrinology 153, 6104-6113.

Honscha, K.U., Schirmer, A., Reischauer, A., Schoon, H.A., Einspanier, A., Gabel, G., 2009. Expression of ABC-transport proteins in canine mammary cancer: consequences for chemotherapy. Reprod. Domest. Anim. 44 (Suppl 2), 218-223.

Huang, Y., Anderle, P., Bussey, K.J., Barbacioru, C., Shankavaram, U., Dai, Z., Reinhold, W.C., Papp, A., Weinstein, J.N., Sadee, W., 2004. Membrane transporters and channels: role of the transportome in cancer chemosensitivity and chemoresistance. Cancer Res. 64, 4294-4301.

Kourti, M., Vavatsi, N., Gombakis, N., Sidi, V., Tzimagiorgis, G., Papageorgiou, T., Koliouskas, D., Athanassiadou, F., 2007. Expression of multidrug resistance 1 (MDR1), multidrug resistance-related protein 1 (MRP1), lung resistance protein (LRP), and breast cancer resistance protein (BCRP) genes and clinical outcome in childhood acute lymphoblastic leukemia. Int. J. Hematol. 86, 166-173.

Lee, J.J., Hughes, C.S., Fine, R.L., Page, R.L., 1996. P-glycoprotein expression in canine lymphoma: a relevant, intermediate model of multidrug resistance. Cancer 77, 1892-1898.

Ma, L., Pratt, S.E., Cao, J., Dantzig, A.H., Moore, R.E., Slapak, C.A., 2002. Identification and characterization of the canine multidrug resistance-associated protein. Mol. Cancer. Ther. 1, 1335-1342.

Maliepaard, M., Scheffer, G.L., Faneyte, I.F., van Gastelen, M.A., Pijnenborg, A.C., Schinkel, A.H., van De Vijver, M.J., Scheper, R.J., Schellens, J.H., 2001. Subcellular localization and distribution of the breast cancer resistance protein transporter in normal human tissues. Cancer Res. 61, 3458-3464.

Marconato, L., Stefanello, D., Valenti, P., Bonfanti, U., Comazzi, S., Roccabianca, P., Caniatti, M., Romanelli, G., Massari, F., Zini, E., 2011. Predictors of long-term survival in dogs with high-grade multicentric lymphoma. J. Am. Vet. Med. Assoc. 238, 480-485.

Matsson, P., Pedersen, J.M., Norinder, U., Bergstrom, C.A., Artursson, P., 2009. Identification of novel specific and general inhibitors of the three major human ATP-binding cassette transporters P-gp, BCRP and MRP2 among registered drugs. Pharm. Res. 26, 1816-1831.

Matsuura, S., Koto, H., Ide, K., Fujino, Y., Setoguchi-Mukai, A., Ohno, K., Tsujimoto, H., 2007. Induction of chemoresistance in a cultured canine cell line by retroviral transduction of the canine multidrug resistance 1 gene. Am. J. Vet. Res. 68, 95-100. 
McCubrey, J.A., Steelman, L.S., Abrams, S.L., Lee, J.T., Chang, F., Bertrand, F.E., Navolanic, P.M., Terrian, D.M., Franklin, R.A., D'Assoro, A.B., Salisbury, J.L., Mazzarino, M.C., Stivala, F., Libra, M., 2006. Roles of the RAF/MEK/ERK and PI3K/ PTEN/AKT pathways in malignant transformation and drug resistance. Adv. Enzyme Regul. 46, 249-279.

Mealey, K.L., 2012. ABCG2 transporter: therapeutic and physiologic implications in veterinary species. J. Vet. Pharmacol. Ther. 35 (2), 105-112.

Mealey, K.L., Bentjen, S.A., Gay, J.M., Hosick, H.L., 2003. Dexamethasone treatment of a canine, but not human, tumour cell line increases chemoresistance independent of P-glycoprotein and multidrug resistance-related protein expression. Vet. Comp. Oncol. 1, 67-75.

Nakaichi, M., Taura, Y., Kanki, M., Mamba, K., Momoi, Y., Tsujimoto, H., Nakama, S. 1996. Establishment and characterization of a new canine B-cell leukemia cell line. J. Vet. Med. Sci. 58, 469-471.

Page, R.L., Hughes, C.S., Huyan, S., Sagris, J., Trogdon, M., 2000. Modulation of P-glycoprotein-mediated doxorubicin resistance in canine cell lines. Anticancer Res. 20, 3533-3538.

Piek, C.J., Rutteman, G.R., Teske, E., 1999. Evaluation of the results of a L-asparaginase-based continuous chemotherapy protocol versus a short doxorubicin-based induction chemotherapy protocol in dogs with malignant lymphoma. Vet. Q. 21, 44-49.

Price, G.S., Page, R.L., Fischer, B.M., Levine, J.F., Gerig, T.M., 1991. Efficacy and toxicity of doxorubicin/cyclophosphamide maintenance therapy in dogs with multicentric lymphosarcoma. J. Vet. Int. Med. 5, 259-262.

Scheffer, G.L., Kool, M., Heijn, M., de Haas, M., Pijnenborg, A.C., Wijnholds, J., van Helvoort, A., de Jong, M.C., Hooijberg, J.H., Mol, C.A., van der Linden, M., de Vree, J.M., van der Valk, P., Elferink, R.P., Borst, P., Scheper, R.J., 2000. Specific detection of multidrug resistance proteins MRP1, MRP2, MRP3, MRP5, and MDR3 P-glycoprotein with a panel of monoclonal antibodies. Cancer Res. 60, 5269-5277.

Schleis, S.E., LeBlanc, A.K., Neilsen, N.R., LeBlanc, C.J., 2008. Flow cytometric evaluation of multidrug resistance proteins on grossly normal canine nodal lymphocyte membranes. Am. J. Vet. Res. 69, 1310-1315.

Schlossmacher, G., Stevens, A., White, A., 2011. Glucocorticoid receptor-mediated apoptosis: mechanisms of resistance in cancer cells. J. Endocrinol. 211, 17-25.

Schrickx, J.A., Fink-Gremmels, J., 2008. Implications of ABC transporters on the disposition of typical veterinary medicinal products. Eur. J. Pharmacol. 585, 510-519.

Simon, D., Moreno, S.N., Hirschberger, J., Moritz, A., Kohn, B., Neumann, S., Jurina, K., Scharvogel, S., Schwedes, C., Reinacher, M., Beyerbach, M., Nolte, I., 2008.
Efficacy of a continuous, multiagent chemotherapeutic protocol versus a shortterm single-agent protocol in dogs with lymphoma. J. Am. Vet. Med. Assoc. 232, $879-885$.

Sorenmo, K., Overley, B., Krick, E., Ferrara, T., LaBlanc, A., Shofer, F., 2010. Outcome and toxicity associated with a dose-intensified, maintenance-free CHOP-based chemotherapy protocol in canine lymphoma: 130 cases. Vet. Comp. Oncol. 8, 196-208.

Steingold, S.F., Sharp, N.J., McGahan, M.C., Hughes, C.S., Dunn, S.E., Page, R.L., 1998 Characterization of canine MDR1 mRNA: its abundance in drug resistant cell lines and in vivo. Anticancer Res. 18, 393-400.

Szakacs, G., Paterson, J.K., Ludwig, J.A., Booth-Genthe, C., Gottesman, M.M., 2006 Targeting multidrug resistance in cancer. Nat. Rev. Drug Discov. 5, 219-234.

Tashbaeva, R.E., Hwang, D.N., Song, G.S., Choi, N.H., Lee, J.H., Lyoo, Y.S., Lee, S.J., Jung, D.I., Kim, H.Y., Sur, J.H., 2007. Cellular characterization of multidrug resistance P-glycoprotein, alpha fetoprotein, and neovascular endothelium-associated antigens in canine hepatocellular carcinoma and cirrhotic liver. Vet. Pathol. 44, 600-606.

Teske, E., 1994. Canine malignant lymphoma: a review and comparison with human non-Hodgkin's lymphoma. Vet. Q. 16, 209-219.

Tome, M.E., Frye, J.B., Coyle, D.L., Jacobson, E.L., Samulitis, B.K., Dvorak, K., Dorr, R.T., Briehl, M.M., 2012. Lymphoma cells with increased anti-oxidant defenses acquire chemoresistance. Exp. Ther. Med. 3, 845-852.

Uozurmi, K., Nakaichi, M., Yamamoto, Y., Une, S., Taura, Y., 2005. Development of multidrug resistance in a canine lymphoma cell line. Res. Vet. Sci. 78, 217-224.

Van der Heyden, S., Croubels, S., Gadeyne, C., Ducatelle, R., Daminet, S., Murua Escobar, H., Sterenczak, K., Polis, I., Schauvliege, S., Hesta, M., Chiers, K., 2012. Influence of P-glycoprotein modulation on plasma concentrations and pharmacokinetics of orally administered prednisolone in dogs. Am. J. Vet. Res. 73, 900-907.

Van der Heyden, S., Vercauteren, G., Daminet, S., Paepe, D., Chiers, K., Polis, I. Waelbers, T., Hesta, M., Schauvliege, S., Wegge, B., Ducatelle, R., 2011. Expression of P-glycoprotein in the intestinal epithelium of dogs with lymphoplasmacytic enteritis. J. Comp. Pathol. 145, 199-206.

Zandvliet, M., Rutteman, G.R., Teske, E., 2013. Prednisolone inclusion in a first-line multidrug cytostatic protocol for the treatment of canine lymphoma does not affect therapy results. Vet. J. 197, 656-661.

Zhu, F., Wang, Y., Zeng, S., Fu, X., Wang, L., Cao, J., 2009. Involvement of annexin A1 in multidrug resistance of K562/ADR cells identified by the proteomic study. OMICS 13, 467-476. 